\title{
A comparison of minimally invasive posterior cervical decompression and open anterior cervical decompression and instrumented fusion in the surgical management of degenerative cervical myelopathy
}

\author{
Syed F. Abbas, BA, ${ }^{1}$ Morgan P. Spurgas, BS, ${ }^{1}$ Benjamin S. Szewczyk, BS, ${ }^{1}$ Benjamin Yim, MD, ${ }^{2}$ \\ Ashar Ata, MBBS, MPH, PhD, ${ }^{3}$ and John W. German, MD² \\ ${ }^{1}$ Albany Medical College, and ${ }^{2}$ Departments of Neurosurgery and ${ }^{3}$ Surgery, Albany Medical College, Albany, New York
}

OBJECTIVE Minimally invasive posterior cervical decompression (miPCD) has been described in several case series with promising preliminary results. The object of the current study was to compare the clinical outcomes between patients undergoing miPCD with anterior cervical discectomy and instrumented fusion (ACDFi).

METHODS A retrospective study of 74 patients undergoing surgery (45 using miPCD and 29 using ACDFi) for myelopathy was performed. Outcomes were categorized into short-term, intermediate, and long-term follow-up, corresponding to averages of 1.7, 7.7, and 30.9 months, respectively. Mean scores for the Neck Disability Index (NDI), neck visual analog scale (VAS) score, SF-12 Physical Component Summary (PCS), and SF-12 Mental Component Summary (MCS) were compared for each follow-up period. The percentage of patients meeting substantial clinical benefit (SCB) was also compared for each outcome measure.

RESULTS Baseline patient characteristics were well-matched, with the exception that patients undergoing miPCD were older (mean age $57.6 \pm 10.0$ years [miPCD] vs $51.1 \pm 9.2$ years [ACDFi]; $p=0.006$ ) and underwent surgery at more levels (mean $2.8 \pm 0.9$ levels [miPCD] vs $1.5 \pm 0.7$ levels [ACDFi]; $p<0.0001$ ) while the ACDFi patients reported higher preoperative neck VAS scores (mean $3.8 \pm 3.0$ [miPCD] vs $5.4 \pm 2.6$ [ACDFi]; $p=0.047$ ). The mean PCS, NDI, neck VAS, and MCS scores were not significantly different with the exception of the MCS score at the short-term follow-up period (mean $46.8 \pm 10.6$ [miPCD] vs $41.3 \pm 10.7$ [ACDFi]; $p=0.033$ ). The percentage of patients reporting SCB based on thresholds derived for PCS, NDI, neck VAS, and MCS scores were not significantly different, with the exception of the PCS score at the intermediate follow-up period (52\% [miPCD] vs $80 \%$ [ACDFi]; $p=0.011$ ).

CONCLUSIONS The current report suggests that the optimal surgical strategy in patients requiring dorsal surgery may be enhanced by the adoption of a minimally invasive surgical approach that appears to result in similar clinical outcomes when compared with a well-accepted strategy of ventral decompression and instrumented fusion. The current results suggest that future comparative effectiveness studies are warranted as the miPCD technique avoids instrumented fusion.

http://thejns.org/doi/abs/10.3171/2016.3.FOCUS1650

KEY WORDS cervical; myelopathy; outcome; spine; substantial clinical benefit

$\mathrm{D}$ EGENERATIVE cervical myelopathy (DCM) is a recently introduced term that encompasses degenerative etiologies of cervical myelopathy including spondylosis, ossification of the posterior longitudinal ligament, and ossification of the ligamentum flavum. ${ }^{22,26} \mathrm{~Pa}-$ tients with progressive myelopathy are often offered surgi- cal treatment to help stabilize or improve their neurological symptoms and function. ${ }^{8}$ To date, the specific choice of surgical treatment of such patients remains unclear and specific guidelines regarding the choice of surgical technique for specific patient types are lacking. The AANS/ CNS Guidelines for the Management of Cervical Degen-

ABBREVIATIONS ACDFi = anterior cervical discectomy and instrumented fusion; $A U C=$ area under the curve; $D C M=$ degenerative cervical myelopathy; $M C I D=$ minimal clinically important difference; MCS = Mental Component Summary; miPCD = minimally invasive posterior cervical decompression; $\mathrm{mJOA}=$ modified Japanese Orthopaedic Association scale; NDI = Neck Disability Index; PCS = Physical Component Summary; SCB = substantial clinical benefit; VAS = visual analog scale.

SUBMITTED January 31, 2016. ACCEPTED March 7, 2016.

INCLUDE WHEN CITING DOI: 10.3171/2016.3.FOCUS1650. 
erative Disease devote 4 chapters to the surgical management of myelopathy, including specific chapters devoted to the surgical techniques of laminectomy, ${ }^{23}$ laminoplasty, ${ }^{17}$ laminectomy with instrumented fusion, ${ }^{1}$ and anterior cervical decompression with instrumented fusion. ${ }^{18}$ These reviews suggest a clear need for more comparative studies of both existing and novel surgical techniques employed in the management of patients with DCM. None of the guideline chapters address the recent introduction of minimally invasive spinal surgical techniques in the management of DCM. Hypothetically, minimally invasive surgical techniques may offer advantages over open posterior cervical surgical techniques by limiting approach-related injury to the paraspinous muscles, posterior ligamentous complex, and facet joints.

Currently, clinical outcomes following spinal surgery are believed to be best measured through the use of well-established patient-reported outcome measures. While in the past the documentation of improved clinical outcomes using patient-reported outcome has proved challenging ${ }_{1}^{14}$ more recent studies have reported improvements after spine surgery with patient-reported outcome measures. ${ }^{2,3,6,8,11,15,19-21,25,30}$ Some may argue that clinical outcome following surgery for DCM is best assessed by a disease-specific measure of neurological disability such as the modified Japanese Orthopaedic Association (mJOA) scale score. While widely reported in the literature, the mJOA is an investigator-administered tool, not a patientreported outcome, and may have poor discrimination in predicting clinical outcome from the perspective of the patient. ${ }^{15,30}$ Prior work from our group suggests that the SF-12 Physical Component Summary (PCS) is more discriminatory than the mJOA and may be less affected by length of follow-up than other scores (B Yim, A Ata, JW German: Defining substantial clinical benefit in patients undergoing surgery for cervical spondylotic myelopathy. Presentation to the 2014 AANS Annual Meeting, San Francisco, California, April 5, 2014). A potential concern of using the PCS as a primary outcome measure is that it represents a measure of general health rather than a disease-specific measure. Despite this concern, patient-reported general health outcome measures have been used in clinical studies addressing spinal surgery outcomes. ${ }^{2-4,6,30,32}$ Another challenge that arises from the use of these questionnaires to measure clinical outcomes is the threshold at which true clinical benefit is present. In the current study, substantial clinical benefit (SCB) was chosen as the cutoff threshold as this represents a definite clinical improvement, whereas the minimal clinically important difference (MCID) represents the threshold where patients may just begin to report a clinically meaningful improvement. ${ }^{10}$

The goal of the current study was to provide comparative data regarding clinical outcomes using well-established patient-reported outcome measures in patients undergoing surgery for symptomatic DCM using either minimally invasive posterior cervical decompression (miPCD) or open anterior cervical decompression and instrumented fusion (ACDFi).

\section{Methods}

The current study was approved by the Institutional Re- view Board of Albany Medical College. A retrospective review was undertaken of 74 consecutive patients operated upon by the senior author (J.W.G.) between September 1, 2005, and December 31, 2014. Patients were identified using the departmental billing database as undergoing cervical spine surgery by the senior author. A total of 377 cervical spine cases was identified and the medical records were reviewed for inclusion and exclusion criteria as described below. Seventy-four patients were identified as meeting criteria and were included in the current study. All patients presented with progressive cervical myelopathy for which surgical intervention was offered. Patients underwent preoperative advanced imaging in the form of MRI or CT myelography as well as dynamic radiography to assess dynamic instability. Patients completed wellestablished patient-derived outcome questionnaires in the normal process of care.

\section{Inclusion/Exclusion Criteria}

Study inclusion criteria included: 1) age greater than 35 years; 2) a diagnosis of progressive DCM; 3) surgery between C-2 and C-7, using either ACDFi or miPCD without fusion; 4) English language fluency; and/or 5) minimal follow-up time of 90 days. Exclusion criteria included: 1) incarceration at the time of surgery; 2) history of prior cervical spinal surgery; 3 ) admission for acute spinal cord injury, including central cord syndrome within last month; and/or 4) history of cervical spine trauma, infection, or tumor.

\section{Surgical Procedures}

Patients in both groups were treated under general anesthesia with electrophysiological monitoring including motor evoked potentials, somatosensory evoked potentials, and continuous electromyography of select muscles. Intraoperative fluoroscopy was used in all cases. Postoperatively patients were mobilized on arrival to the floor and rehab assessments were made as part of hospital policy for any patient with poor mobility.

\section{Anterior Cervical Decompression and Instrumented Fusion}

Patients treated with ACDFi were positioned supine with a specific effort to optimize cervical lordosis with positioning. All patients underwent a standard approach through a right-sided transverse incision, extending from near the midline to the medial border of the sternocleidomastoid muscle. The platysma muscle was divided and the dissection was deepened along the medial border of the sternocleidomastoid muscle onto the ventral aspect of the spine. The correct level was confirmed fluoroscopically using a bent spinal needle inserted into a disc space. Once the correct level had been identified, the operative microscope was brought into use. Using a microsurgical technique the interspace was exposed in a subperiosteal fashion to the uncovertebral joints bilaterally and self-retaining retractors were placed. Distraction pins were placed in the vertebral bodies above and below the disc space. The ventral osteophytes were drilled down to the level of the midvertebral bodies to accommodate anterior cervical instrumentation. A discectomy was performed to the level of the posterior 
longitudinal ligament, at which point a drill was used to thin the posterior osteophytes and bilateral anterior foraminotomies. The posterior longitudinal ligament was then resected and anterior foraminotomies were completed. The interspace was sized and the endplates decorticated with rasps and a drill. Interbody fusion was performed with machined corticocancellous graft, which was compressed by releasing the distraction pins. For patients with significant retrovertebral compression a corpectomy was performed. Local autograft was harvested and packed into a cage that was placed into the defect. All patients underwent application of anterior cervical instrumentation with fluoroscopy using a translational plate. The wound was then closed in the standard fashion. A representative case of ACDFi is presented in Figs. 1 and 2.

\section{Minimally Invasive Posterior Cervical Decompression}

Patients treated with miPCD were positioned prone with specific effort to obtain a true neck-neutral position with capital flexion. All patients underwent a percutaneous fluoroscopically guided approach. Prior to incision both the anatomical midline as well as the upper and lower spinous processes of the affected levels were identified and marked in ink on the drapes. A midline skin incision was made from the upper spinous process to the lowest spinous process and the dissection taken to the cervical fascia. The fascia was divided 1 centimeter to the side of approach. Note that a wire was not used to gain spinal access. A clamp was used to spread the trapezius muscle fibers open while a second clamp was used with fluoroscopic guidance to gain access to the spinous process and lamina. Once the lamina was palpated, the second clamp was spread, allowing the initial soft-tissue dilator to be placed directly onto the lamina. Under fluoroscopy, additional soft-tissue dilators were applied to a final diameter of 18 millimeters, over which a tubular retractor of appro- priate length was placed. The operative microscope was brought into use. Using a microsurgical technique a subperiosteal dissection was performed, exposing the entire length of the lamina and adjacent interspaces. An ipsilateral hemilaminectomy was performed using a drill while leaving the underlying ligamentum in place to protect the underlying dura. The tubular retractor was directed to the base of the spinous process, which is thinned with the drill to expose the contralateral lamina. The contralateral lamina is resected using the drill while again protecting the underlying dura by leaving the ligamentum intact. In this manner the contralateral canal is decompressed. The ligamentum is then elevated off the dura and resected. Epidural hemostasis is obtained and confirmed by return of clear irrigation. Depending on patient-specific anatomy, additional levels were then decompressed by redirecting the tubular retractor. If additional access is required the initial tubular retractor is directed over the edge of the decompression and access to the adjacent level is made as described above, using 2 clamps under fluoroscopic guidance. Once all levels have been decompressed the tubular retractor is withdrawn while obtaining muscle hemostasis. The wound is irrigated and closed in layers using loose absorbable sutures for the trapezius muscle and specific care is taken to close the fascia tightly. A representative case of miPCD is presented in Figs. 3 and 4.

\section{Primary Outcome Measure}

The SF-12 PCS was chosen as the primary outcome measure based on prior reports suggesting that this patient-reported outcome measure was one of the most discriminatory measures in determining outcome in prior investigations of patients undergoing surgery for DCM, as validated by its high area under the curve (AUC) in receiver operating characteristic (ROC) curve analysis., 2,3,6,32 Additionally, an ongoing randomized, prospective trial of
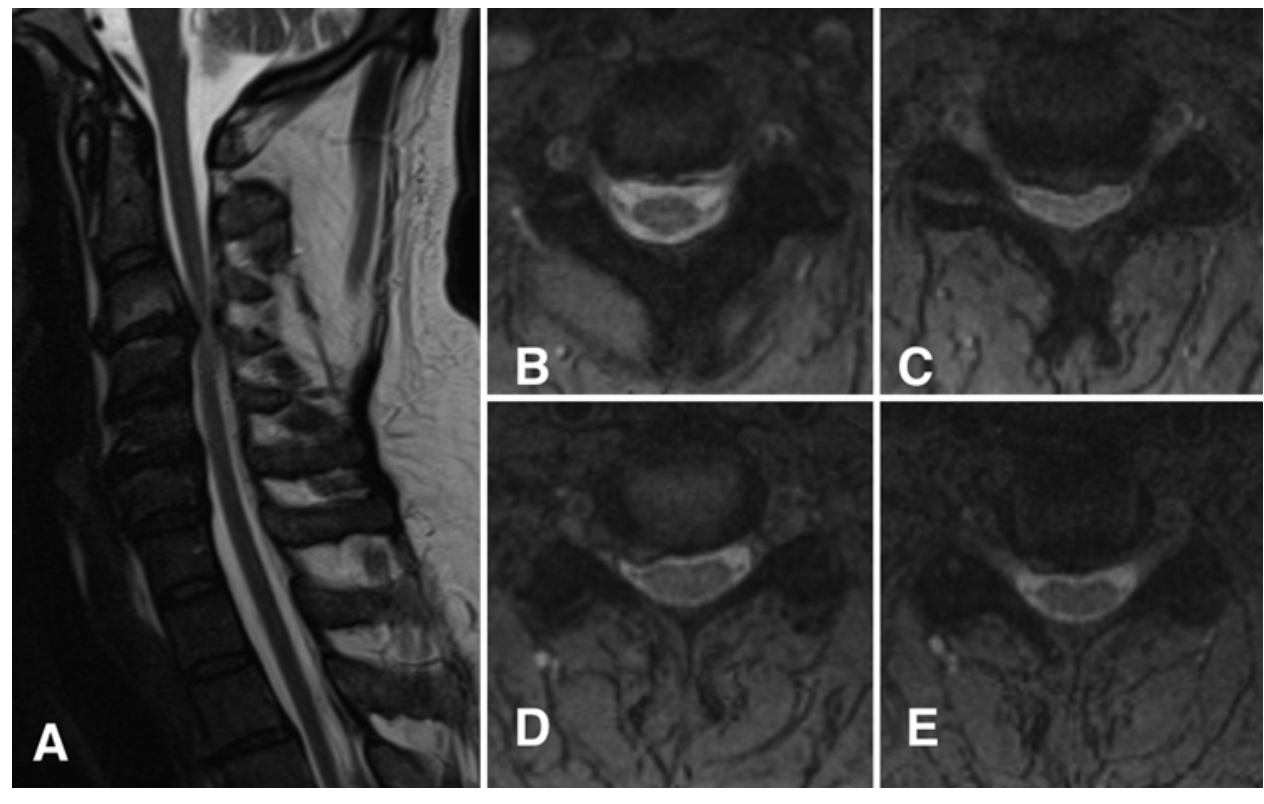

FIG. 1. Preoperative T2-weighted MRI of the cervical spine for an ACDFi candidate. Sagittal (A) and axial views of C2-3 (B), C3-4 (C), C4-5 (D), and C5-6 (E), demonstrating critical cord stenosis at C3-4. 


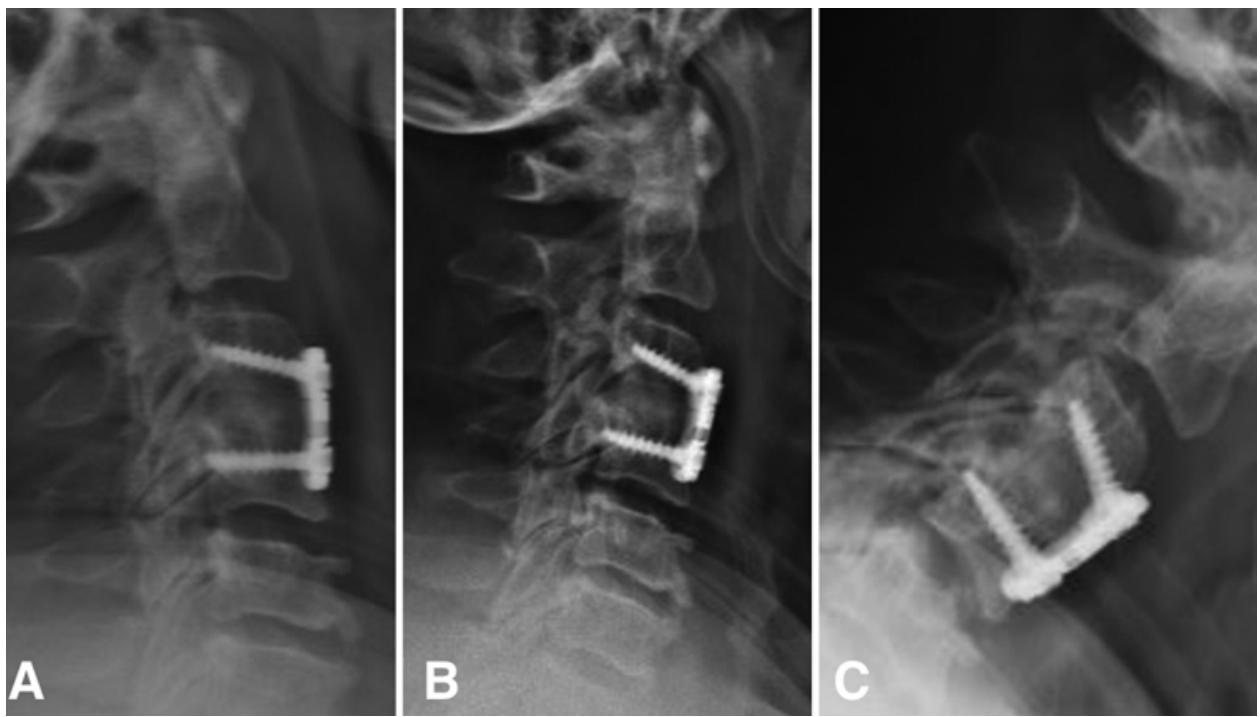

FIG. 2. Postoperative plain film radiograph of the cervical spine for a patient who underwent ACDFi. Extension (A), neutral (B), and flexion (C) films for a patient presenting with cervical myelopathy following anterior cervical reconstruction at C3-4.

the surgical management of DCM has also identified PCS as an appropriate primary outcome measure. ${ }^{10}$ The SF-12 survey provides the PCS and the Mental Component Summary (MCS), measuring an individual's self-reported general health; it is not a disease-specific tool for the study of myelopathy. Both PCS and MCS are scored out of a 100, with a score of $50 \pm 10$, equating to the mean score of the US population. ${ }^{29}$

\section{Secondary Outcome Measures}

The Neck Disability Index (NDI), neck visual analog scale (VAS) score, and SF-12 MCS were used as secondary outcome measures. The NDI is a derivation of the Oswestry Disability Index, and is one of the most com- monly used tools to assess neck disability. It is a 10-question survey with each question scored from 0 to 5 , which can be converted into a percentage quantifying the level of disability. ${ }^{28}$ The neck VAS assesses a patient's pain level, asking them to draw an "X" on a $10-\mathrm{cm}$ line without the constraints of a numeric pain scale.

\section{Sample Size Estimate}

A sample size of 25 for each group was estimated using JMP Pro (version 11 for Windows 7, SAS) with the following variables: difference in PCS of 6.5 between the groups to represent a change corresponding to substantial clinical benefit, ${ }^{6}$ a PCS standard deviation of $8.0,{ }^{6}$ an $\alpha$ of 0.05 , and power of 0.80 .
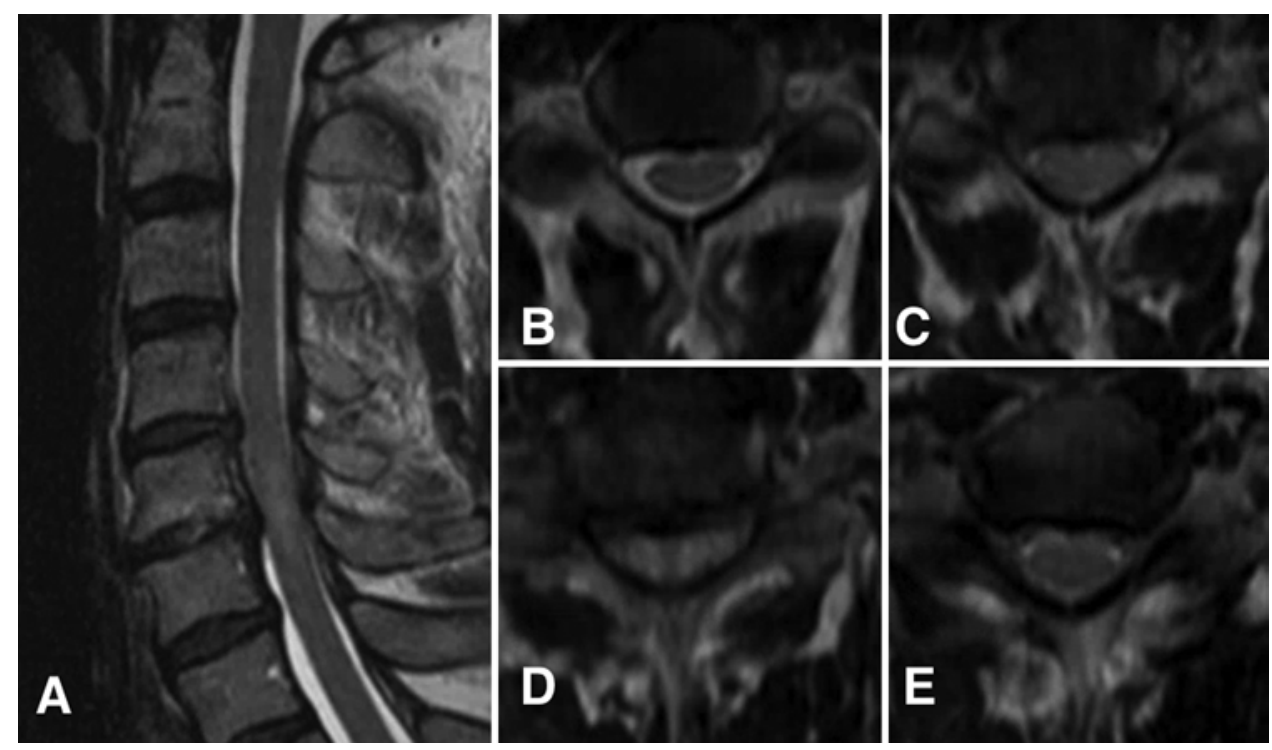

FIG. 3. Preoperative T2-weighted MRI of the cervical spine for an miPCD candidate. Sagittal (A) and axial views of C3-4 (B), C4-5 (C), C5-6 (D), and C6-7 (E), demonstrating critical cord stenosis, particularly at C4-6. 

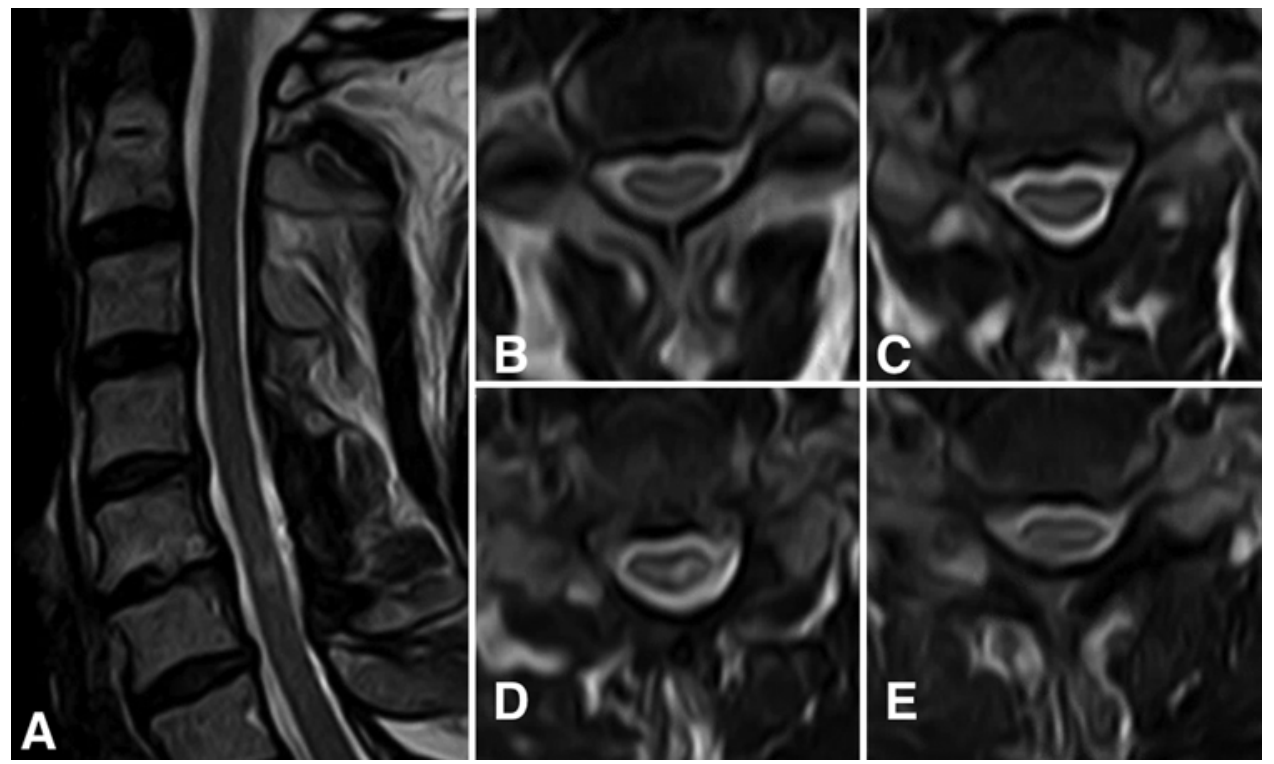

FIG. 4. Postoperative T2-weighted MRI of the cervical spine following C4-7 posterior decompression. Sagittal (A) and axial views of C3-4 (B), C4-5 (C), C5-6 (D), and C6-7 (E).

\section{Patient Characteristics}

Medical records were abstracted for the following data elements: age, sex, weight, height, race, tobacco use, number of medical comorbidities, medications, insurance status, education, and baseline mJOA score.

\section{Surgical Characteristics}

Medical records were reviewed to confirm that the patient received 1 of the 2 index surgical procedures. Other data elements abstracted included number of spinal levels treated, estimated blood loss, intravenous fluids, transfusions, and dural tears.

\section{Generation of ROC Curves}

The 74 patients included in this study completed 439 questionnaires as part of routine clinical care. Responses were first divided by length of follow-up into tertiles, resulting in 3 groups with average postoperative follow-up intervals of 1.7, 7.7, and 30.9 months corresponding to short-, intermediate-, and long-term follow-up. SCB was chosen as the cutoff threshold as this represents a definite clinical improvement whereas the MCID represents the threshold where patients may just begin to report a clinical improvement. ${ }^{11}$ To determine substantial clinical benefit, the patient satisfaction index was used as an anchor. Patients were asked to select the best response for the question, "Would you have the same treatment again for the same condition (circle one)?" The 5 responses included "Definitely not," "Probably not," "Not sure," "Probably yes," and "Definitely yes." The data from patients answering "Definitely yes" and "Not sure" were used to calculate ROC curves for each of the 4 patient-derived outcome measures at each of the 3 follow-up intervals, resulting in a total of 12 curves.

\section{Calculation of SCB Thresholds}

The percentage of patients achieving the threshold for
SCB for each outcome measure was also calculated based on thresholds from prior work. The threshold cut points corresponding to SCB were defined for each quality of life outcome measure using the technique described by Froud and Abel. ${ }^{9}$ The AUC quantifies the ability of a given measure to correctly classify a sample in the 2 previously defined states, those substantially benefiting from surgery and those who did not. An AUC of 0.5 suggest no discrimination, between 0.7 and 0.8 is acceptable, $0.8-0.9$ is excellent, and 0.9-1.0 constitutes superior discrimination.

\section{Statistical Analysis}

Statistical analysis was performed using JMP Pro (version 11 for Windows 7, SAS). SCB thresholds for a given patient-derived outcome measure were determined by maximizing sensitivity and specificity by minimizing the sums of their squares. This method reports the cut point that is closest to the upper left portion of the ROC curve (sensitivity, 1-specificity), thus minimizing selection bias when generating thresholds. ${ }^{8}$ Mean outcome scores for NDI, neck VAS, SF-12 PCS, and SF-12 MCS were compared for each follow-up period. The percentage of patients meeting SCB based on previously calculated thresholds were also compared for each outcome measure. Statistical analysis was conducted with the Student t-test and Pearson chi-square test, with $\mathrm{p}<0.05$ considered significant.

\section{Results}

\section{Patient Characteristics}

Baseline patient characteristics are summarized in Table 1 while surgical characteristics are shown in Table 2 . No statistical difference was noted in baseline mJOA score (mean $12.6 \pm 2.6[\mathrm{miPCD}]$ vs $12.8 \pm 2.6[\mathrm{ACDFi}] ; \mathrm{p}=$ 0.719). Baseline patient characteristics were well matched with the exception that patients undergoing miPCD were older (mean $57.6 \pm 10.0$ years [miPCD] vs $51.1 \pm 9.2$ years 
TABLE 1. Baseline patient characteristics

\begin{tabular}{|c|c|c|c|}
\hline Variable & miPCD & ACDFi & $\begin{array}{c}p \\
\text { Value }\end{array}$ \\
\hline No. of patients & 45 & 29 & \\
\hline Mean age \pm SD (yrs) & $57.6 \pm 10.0$ & $51.1 \pm 9.2$ & $0.006^{*}$ \\
\hline$\%$ males & 71.1 & 79.3 & 0.431 \\
\hline Mean height \pm SD (in) & $68.5 \pm 4.1$ & $68.3 \pm 3.2$ & 0.734 \\
\hline Mean weight \pm SD (lbs) & $192.2 \pm 47.9$ & $203.7 \pm 44.9$ & 0.298 \\
\hline Mean BMI $\pm \mathrm{SD}\left(\mathrm{kg} / \mathrm{m}^{2}\right)$ & $29.2 \pm 5.9$ & $30.6 \pm 5.1$ & 0.279 \\
\hline Race (\%) & & & 0.616 \\
\hline Caucasian & 76 & 86 & \\
\hline African-American & 9 & 3 & \\
\hline Asian/Indian & 2 & 0 & \\
\hline Unknown & 13 & 10 & \\
\hline $\begin{array}{l}\text { Mean mJOA myelopathy } \\
\text { score } \pm \text { SD }\end{array}$ & $12.6 \pm 2.6$ & $12.8 \pm 2.6$ & 0.719 \\
\hline Tobacco use (\%) & 41 & 36 & 0.180 \\
\hline $\begin{array}{l}\text { Mean medical conditions } \\
\quad \pm \mathrm{SD}\end{array}$ & $3.8 \pm 2.9$ & $3.9 \pm 2.5$ & 0.940 \\
\hline \multicolumn{4}{|l|}{ Psychiatric comorbidities (\%) } \\
\hline Depression & 15 & 18 & 0.936 \\
\hline Anxiety & 15 & 7 & 0.588 \\
\hline Substance abuse & 7 & 11 & 0.793 \\
\hline Mean prescription meds \pm SD & $5.3 \pm 4.3$ & $6.0 \pm 4.6$ & 0.473 \\
\hline \multicolumn{4}{|l|}{ Medication type (\%) } \\
\hline Antidepressant & 13 & 14 & 0.996 \\
\hline NSAID & 33 & 41 & 0.752 \\
\hline Muscle relaxant & 11 & 7 & 0.774 \\
\hline Short-acting narcotic & 24 & 34 & 0.618 \\
\hline Long-acting narcotic & 0 & 4 & 0.453 \\
\hline Non-narcotic pain med & 7 & 10 & 0.846 \\
\hline Neuromodulating agent & 16 & 24 & 0.637 \\
\hline Insurance type (\%) & & & 0.356 \\
\hline Private & 36 & 41 & \\
\hline Medicare & 24 & 14 & \\
\hline Medicaid & 24 & 21 & \\
\hline Workman's compensation & 0 & 7 & \\
\hline Unknown & 16 & 17 & \\
\hline Education completed (\%) & & & 0.355 \\
\hline Graduate & 9 & 0 & \\
\hline College & 27 & 24 & \\
\hline High school & 38 & 38 & \\
\hline Less than high school & 7 & 4 & \\
\hline Unknown & 20 & 34 & \\
\hline
\end{tabular}

$\mathrm{BMI}=$ body mass index; med = medication; NSAID = nonsteroidal antiinflammatory drug.

* Statistically significant $(p<0.05)$.

[ACDFi]; $\mathrm{p}=0.006$ ) and underwent surgery at more levels (mean $2.8 \pm 0.9$ levels $[\mathrm{miPCD}]$ vs $1.5 \pm 0.7$ levels [ACDFi]; $p<0.0001)$ while the ACDFi patients reported higher preoperative neck VAS scores (mean $3.8 \pm 3.0$ [miPCD] vs $5.4 \pm 2.6$ [ACDFi]; $\mathrm{p}=0.047$; Table 3).
TABLE 2. Surgical characteristics

\begin{tabular}{lccc}
\hline \multicolumn{1}{c}{ Characteristic } & miPCD & ACDFi & p Value \\
\hline Mean mJOA score \pm SD & $12.6 \pm 2.6$ & $12.8 \pm 2.6$ & 0.717 \\
\hline Mean no. of levels \pm SD & $2.8 \pm 0.9$ & $1.5 \pm 0.7$ & $<0.0001$ \\
\hline Mean IV fluid \pm SD $(\mathrm{ml})$ & $2824.1 \pm 872.4$ & $2464 \pm 692.1$ & 0.072 \\
\hline Mean EBL \pm SD $(\mathrm{ml})$ & $98.8 \pm 132.1$ & $106.2 \pm 71.3$ & 0.775 \\
\hline Transfusion $(\%)$ & 2.6 & 0 & 0.420 \\
\hline Dural tear $(\%)$ & 1 & 1 & 0.777 \\
\hline
\end{tabular}

$\mathrm{EBL}=$ estimated blood loss; IV = intravenous.

\section{Patient-Derived Outcome Measures}

Representative receiver operator curves are illustrated in Fig. 5 for the primary outcome measure of PCS at each of the 3 follow-up periods (short-term, intermediate, and long-term). The AUC for the 3 curves was 0.730, 0.905, and 0.740 , representing acceptable to excellent levels of discrimination.

Results of patient-reported outcome measures are summarized in Tables 3 and 4. The mean PCS, NDI, neck VAS, and MCS scores were statistically similar at all time periods with the exception of the MCS score at the shortterm follow-up period (mean $46.8 \pm 10.6$ [miPCD] vs 41.3 \pm 10.7 [ACDFi]; $p=0.033$ ). The percentage of patients reporting SCB based on thresholds derived for PCS, NDI, neck VAS, and MCS were statistically similar at all time periods with the exception of the PCS score at the intermediate follow-up period (52\% [miPCD] vs $80 \%$ [ACDFi]; $\mathrm{p}=0.011 ;$ Table 4).

TABLE 3. Mean values of patient-reported outcome measures in the miPCD and ACDFi groups

\begin{tabular}{|c|c|c|c|}
\hline Scale & miPCD* & $\mathrm{ACDFi}^{*}$ & $p$ Value \\
\hline \multicolumn{4}{|l|}{ SF-12 PCS } \\
\hline Preop & $32.3 \pm 7.9$ & $30.9 \pm 8.6$ & 0.542 \\
\hline Short-term & $33.1 \pm 9.6$ & $31.5 \pm 7.1$ & 0.402 \\
\hline Intermediate & $34.8 \pm 11.0$ & $38.0 \pm 9.2$ & 0.149 \\
\hline Long-term & $33.7 \pm 10.5$ & $36.0 \pm 9.3$ & 0.402 \\
\hline \multicolumn{4}{|l|}{ NDI } \\
\hline Preop & $34.4 \pm 21.5$ & $43.1 \pm 17.5$ & 0.087 \\
\hline Short-term & $34.3 \pm 21.1$ & $41.8 \pm 18.4$ & 0.074 \\
\hline Intermediate & $24.0 \pm 18.8$ & $27.3 \pm 19.0$ & 0.395 \\
\hline Long-term & $39.6 \pm 28.4$ & $33.6 \pm 24.4$ & 0.258 \\
\hline \multicolumn{4}{|l|}{ Neck VAS } \\
\hline Preop & $3.8 \pm 3.0$ & $5.4 \pm 2.6$ & $0.047 \dagger$ \\
\hline Short-term & $2.5 \pm 2.5$ & $3.1 \pm 2.8$ & 0.305 \\
\hline Intermediate & $2.0 \pm 2.5$ & $2.4 \pm 2.6$ & 0.485 \\
\hline Long-term & $2.9 \pm 2.6$ & $2.7 \pm 2.8$ & 0.684 \\
\hline \multicolumn{4}{|l|}{ SF-12 MCS } \\
\hline Preop & $43.3 \pm 13.1$ & $41.4 \pm 10.5$ & 0.550 \\
\hline Short-term & $46.8 \pm 10.6$ & $41.3 \pm 10.7$ & $0.033 \dagger$ \\
\hline Intermediate & $45.4 \pm 11.0$ & $47.3 \pm 11.4$ & 0.447 \\
\hline Long-term & $41.8 \pm 12.9$ & $47.3 \pm 11.9$ & 0.050 \\
\hline
\end{tabular}

* Data given as mean $\pm \mathrm{SD}$.

$\dagger$ Statistically significant $(p<0.05)$. 

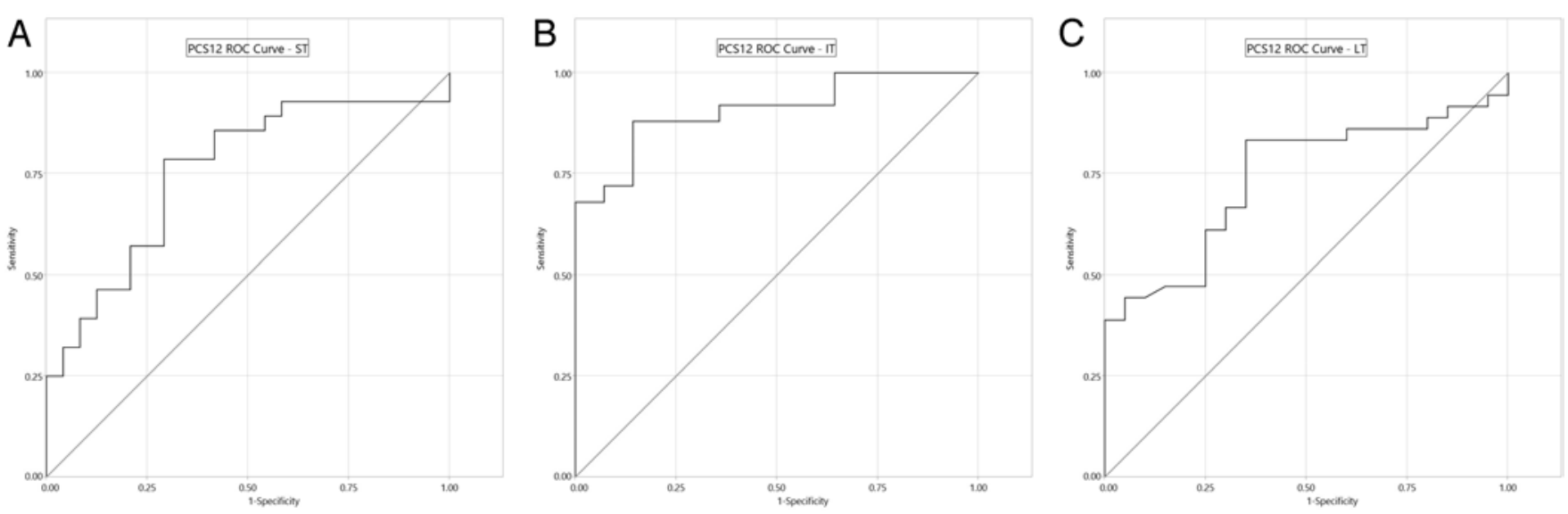

FIG. 5. ROC curves for the primary outcome measure of the SF-12 (PCS) at short-term (A), intermediate (B), and long-term (C) follow-up. The calculations were made using the Patient Satisfaction Index as an anchor. Corresponding areas of the curve are $0.730,0.905$, and 0.740 , respectively.

\section{Discussion \\ Clinical Implications}

The current results suggest that equivalent clinical outcomes can be achieved using miPCD and ACDFi. It should be noted that significant baseline differences were found between the groups. The miPCD patients were on average older and underwent surgery on more spinal segments while the ACDFi patients reported higher neck VAS scores at baseline. These factors could certainly influence the clinical outcomes observed in this study and are discussed below.

With respect to age, the observations of the current study are similar to those reported by Nakashima et al. in a recently reported global survey of the surgical management of DCM patients. In this study older patients tended to undergo posterior surgery while younger patients were more likely to receive an anterior procedure. ${ }^{21}$ Older age is one factor that may limit clinical outcome with several authors reporting worse outcomes in older patients. ${ }^{12,16,21,27}$ Older age may also be associated with either more diffuse degenerative changes or a predilection for affecting the higher cervical segment. Both of these factors may affect surgical decision-making. The senior author's bias is to limit the use of ACDFi in older patients as the $\mathrm{C} 3-4$ and C4-5 segments rather than the C5-6 and C6-7 segments are more likely to be symptomatic.

With respect to the number of levels treated, the observations of the current study that miPCD patients underwent surgery at more levels than the ACDFi patients is not surprising. The posterior approach is often favored for the management of diffuse disease particularly in the setting of preserved lordosis. As the clinical experience of miPCD grew the senior author's bias has evolved to favor this approach in most patients presenting with greater than 2-level disease.

With respect to axial pain, the observation that the ACDFi patients reported statistically higher neck VAS scores is not surprising because many surgeons favor a ventral approach to manage comorbid axial pain. Traditionally, the ventral approach avoids the extensive softtissue dissection used in the open techniques of laminec- tomy, laminoplasty, and laminectomy with instrumented fusion. Avoiding this dissection may improve clinical outcomes and may explain a trend toward more limited forms of laminoplasty.

The question of which surgical approach to apply to a specific patient remains a clinically important question for spine surgeons and the primary focus of an ongoing clinical trial. ${ }^{10}$ Multiple factors may influence the surgical decision-making including pathoanatomical factors, patientspecific factors, and surgical factors. Pathoanatomical factors may include the primary site of compression (ventral vs dorsal), the extent of compression (focal vs diffuse), the

TABLE 4. Percentage of patients meeting the threshold for SCB

\begin{tabular}{cccc}
\hline Scale & miPCD & ACDFi & p Value \\
\hline NDI (\%) & & & \\
\hline Short-term & 52 & 40 & 0.240 \\
\hline Intermediate & 65 & 61 & 0.690 \\
\hline Long-term & 32 & 26 & 0.442 \\
\hline Neck VAS (\%) & & & \\
\hline Short-term & 66 & 63 & 0.736 \\
\hline Intermediate & 53 & 51 & 0.898 \\
\hline Long-term & 48 & 53 & 0.679 \\
\hline SF-12 PCS (\%) & & & \\
\hline Short-term & 61 & 52 & 0.444 \\
\hline Intermediate & 52 & 80 & $0.011^{*}$ \\
\hline Long-term & 53 & 67 & 0.206 \\
\hline SF-12 MCS (\%) & & & \\
\hline Short-term & 55 & 33 & 0.060 \\
\hline Intermediate & 47 & 59 & 0.289 \\
\hline Long-term & 26 & 39 & 0.207 \\
\hline mJOA (\%) & & & \\
\hline Short-term & 59 & 48 & 0.399 \\
\hline Intermediate & 50 & 42 & 0.480 \\
\hline Long-term & 25 & 32 & 0.508 \\
\hline
\end{tabular}

* Statistically significant $(p<0.05)$. 
presence of dynamic instability potentially requiring instrumented fusion, the presence of significant deformity, and the type of cervical spinal curvature. Patient-specific factors may include the presence of significant axial pain, prior cervical spine or neck surgery, prior radiation, tobacco use, uncontrolled diabetes, immunosuppression, steroid use, osteoporosis, baseline swallowing dysfunction, willingness to accept the risk of changes in voice or swallowing, and patient preference. Ultimately, surgeons managing patients with DCM should be technically competent in the performance of both ventral and dorsal approaches, which may require decompression, fusion, and instrumentation. Given the lack of data to exclusively favor one surgical approach over another, it is paramount that treating surgeons maintain an open frame of mind and engage in a shared decision-making process with the patient.

Some may argue that the assessment of clinical outcome may be better represented by measures of neurological function such as the mJOA rather than by patientderived outcome measures. Proponents of this approach may argue that DCM is a disease of progressive neurological dysfunction and that many patients will chose surgery to maintain but not necessarily improve their neurological function. On this basis, one may certainly argue that an assessment of neurological disability is an appropriate choice of primary outcome measure. Unfortunately, these measures may not represent the best discriminators of clinical outcome from the patient perspective. ${ }^{15,30}$

The current study uses a well-accepted patient-derived outcome measure of PCS as the primary outcome measure rather than the more traditional mJOA myelopathy score. The PCS is a general health measure that may allow for direct comparison with other medical treatments. By comparison, the mJOA is a disease-specific, investigator-derived outcome measure. Our group has presented preliminary evidence that from the patient perspective, the mJOA is a poor discriminator of clinical outcome, with both the PCS and NDI providing better discrimination (B Yim, A Ata, JW German: Defining substantial clinical benefit in patients undergoing surgery for cervical spondylotic myelopathy. Presentation to the 2014 AANS Annual Meeting, San Francisco, California, April 5, 2014). This finding suggests that, from the perspective of patients, factors other than neurological function are important determinants of clinical outcome that are not assessed by the mJOA. For example, the mJOA does not address axial pain that may contribute significantly to clinical outcome from the perspective of the patient. Recently it has been reported that the PCS was chosen as the primary outcome measure for an ongoing trial of ventral versus dorsal surgery for DCM. ${ }^{10}$ For this specific reason the PCS was chosen as the primary outcome measure in the current study.

The assessment of clinical outcome following surgery for DCM remains challenging, with at least 1 early report suggesting no improvement based on several patient-derived outcome measures..$^{14}$ More recent reports have suggested improvement based on such measures. ${ }^{2,3,6,8,11,19,20,25,32}$ The need for a uniform approach in reporting outcomes following spine surgery remains.

The current report suggests that the optimal surgical strategy in patients requiring dorsal surgery may be en- hanced by the adoption of a minimally invasive surgical approach that appears to result in similar clinical outcomes when compared with a well-accepted strategy of ventral decompression and instrumented fusion.

\section{Minimally Invasive Posterior Cervical Decompression for DCM}

Several reports have described the application of a minimally invasive surgical approach to the management of DCM..$^{5,719,20,24,31}$ Most studies represent technical reports or small case series with limited use of patient-derived outcome measures. To date, the largest series of miPCD was that reported by Minamide et al. in which improvements were noted for neck VAS, JOA myelopathy score, and SF-36 scores..$^{20}$ In a more recent study, Minamide et al. used propensity matching to compare 2 groups of 71 patients who had undergone dorsal decompression using either a minimally invasive technique or an open laminoplasty technique..$^{19}$ The patient-reported outcome measures used in this study included the neck VAS score, JOA myelopathy score, the JOA Cervical Myelopathy Evaluation Questionnaire, and SF-36 scores. Postoperative outcomes were similar for these measures with the exception that axial complaints were significantly reduced in the minimally invasive group.

Minimally invasive spine surgery techniques may offer advantages over open posterior cervical surgical techniques by limiting approach-related injury to the paraspinous muscles, posterior ligamentous complex, and facet joints. The potential clinical advantages of using a minimally invasive spinal surgery technique include less blood loss, lower risk of infection, less use of narcotics, earlier return to work or other activity, and less long-term axial pain, while the potential disadvantages include increased technical demands and increased operative time. The current study suggests that a miPCD may result in similar clinical outcomes when compared with an ACDFi. Further surgical parsimony may be gained by using intraoperative electrophysiological techniques..$^{13}$ Once again it is worth noting that the patients undergoing miPCD in this study were older, treated at more levels, had similar lengths of hospitalization, avoided the use of fusion, and avoided the use of spinal instrumentation, suggesting that future studies may focus on health resource utilization and costeffectiveness.

\section{Study Strengths and Limitations}

To our knowledge the current report is the first to compare a minimally invasive surgical technique to anterior cervical decompression and instrumented fusion, which represents a preferred surgical technique in many parts of the world, including North America. ${ }^{8}$ The current study employs well-established patient-derived outcome measures to compare both the mean differences in patient-derived outcome measures as well as the chance of obtaining the SCB threshold representing a point of definitive clinical improvement from the patient perspective.

The retrospective nature of the study results in several limitations, including differences in baseline characteristics, a single surgeon experience, a nonrandomized design, lack of cost data, and several areas of bias, including sur- 
geon preference for a ventral or dorsal approach based on both patient factors, pathoanatomical factors, and a commitment to a shared decision-making process.

\section{Conclusions}

The current retrospective study compared miPCD using a tubular retractor to ACDFi. The patients who underwent a minimally invasive approach were on average older and underwent surgery at more spinal segments, while the patients undergoing an anterior approach reported higher neck VAS scores at baseline. Despite these differences, the patients undergoing miPCD reported outcomes similar to the patients treated with open ACDFi. Future comparative studies are warranted as the avoidance of instrumented fusion may have implications for health resource usage.

\section{References}

1. Anderson PA, Matz PG, Groff MW, Heary RF, Holly LT, Kaiser MG, et al: Laminectomy and fusion for the treatment of cervical degenerative myelopathy. J Neurosurg Spine 11:150-156, 2009

2. Auffinger B, Lam S, Shen J, Thaci B, Roitberg BZ: Usefulness of minimum clinically important difference for assessing patients with subaxial degenerative cervical spine disease: statistical versus substantial clinical benefit. Acta Neurochir (Wien) 155:2345-2355, 2013

3. Auffinger BM, Lall RR, Dahdaleh NS, Wong AP, Lam SK, Koski T, et al: Measuring surgical outcomes in cervical spondylotic myelopathy patients undergoing anterior cervical discectomy and fusion: assessment of minimum clinically important difference. PLoS One 8:e67408, 2013

4. Birkmeyer NJ, Weinstein JN, Tosteson AN, Tosteson TD, Skinner JS, Lurie JD, et al: Design of the Spine Patient Outcomes Research Trial (SPORT). Spine (Phila Pa 1976) 27:1361-1372, 2002

5. Boehm H, Greiner-Perth R, El-Saghir H, Allam Y: A new minimally invasive posterior approach for the treatment of cervical radiculopathy and myelopathy: surgical technique and preliminary results. Eur Spine J 12:268-273, 2003

6. Carreon LY, Glassman SD, Campbell MJ, Anderson PA: Neck Disability Index, Short Form-36 physical component summary, and pain scales for neck and arm pain: the minimum clinically important difference and substantial clinical benefit after cervical spine fusion. Spine J 10:469-474, 2010

7. Dahdaleh NS, Wong AP, Smith ZA, Wong RH, Lam SK, Fessler RG: Microendoscopic decompression for cervical spondylotic myelopathy. Neurosurg Focus 35(1):E8, 2013

8. Fehlings MG, Ibrahim A, Tetreault L, Albanese V, Alvarado M, Arnold P, et al: A global perspective on the outcomes of surgical decompression in patients with cervical spondylotic myelopathy: results from the prospective multicenter AOSpine international study on 479 patients. Spine (Phila Pa 1976) 40:1322-1328, 2015

9. Froud R, Abel G: Using ROC curves to choose minimally important change thresholds when sensitivity and specificity are valued equally: the forgotten lesson of Pythagoras. Theoretical considerations and an example application of change in health status. PLoS One 9:e114468, 2014

10. Ghogawala Z, Benzel EC, Heary RF, Riew KD, Albert TJ, Butler WE, et al: Cervical spondylotic myelopathy surgical trial: randomized, controlled trial design and rationale. Neurosurgery 75:334-346, 2014

11. Glassman SD, Copay AG, Berven SH, Polly DW, Subach BR, Carreon LY: Defining substantial clinical benefit following lumbar spine arthrodesis. J Bone Joint Surg Am 90:18391847,2008
12. Holly LT, Matz PG, Anderson PA, Groff MW, Heary RF, Kaiser MG, et al: Clinical prognostic indicators of surgical outcome in cervical spondylotic myelopathy. J Neurosurg Spine 11:112-118, 2009

13. Kato Y, Kojima T, Kataoka H, Imajo Y, Yara T, Yoshida Y, et al: Selective laminoplasty after the preoperative diagnosis of the responsible level using spinal cord evoked potentials in elderly patients with cervical spondylotic myelopathy: a preliminary report. J Spinal Disord Tech 22:586-592, 2009

14. King JT Jr, Moossy JJ, Tsevat J, Roberts MS: Multimodal assessment after surgery for cervical spondylotic myelopathy. J Neurosurg Spine 2:526-534, 2005

15. Lubelski D, Alvin MD, Nesterenko S, Sundar SJ, Thompson NR, Benzel EC, et al: Correlation of quality of life and functional outcome measures for cervical spondylotic myelopathy. J Neurosurg Spine 24:483-489, 2016

16. Machino M, Yukawa Y, Imagama S, Ito K, Katayama Y, Matsumoto T, et al: Surgical treatment assessment of cervical laminoplasty using quantitative performance evaluation in elderly patients: a prospective comparative study in 505 patients with cervical spondylotic myelopathy. Spine (Phila Pa 1976) 41:757-763, 2016

17. Matz PG, Anderson PA, Groff MW, Heary RF, Holly LT, Kaiser MG, et al: Cervical laminoplasty for the treatment of cervical degenerative myelopathy. J Neurosurg Spine 11:157-169, 2009

18. Matz PG, Holly LT, Mummaneni PV, Anderson PA, Groff MW, Heary RF, et al: Anterior cervical surgery for the treatment of cervical degenerative myelopathy. J Neurosurg Spine 11:170-173, 2009

19. Minamide A, Yoshida M, Yamada H, Hashizume H, Nakagawa Y, Nishi H, et al: Efficacy of posterior segmental decompression surgery for pincer mechanism in cervical spondylotic myelopathy: a retrospective case-controlled study using propensity score matching. Spine (Phila Pa 1976) 40:1807-1815, 2015

20. Minamide A, Yoshida M, Yamada H, Nakagawa Y, Maio $\mathrm{K}$, Kawai M, et al: Clinical outcomes of microendoscopic decompression surgery for cervical myelopathy. Eur Spine J 19:487-493, 2010

21. Nakashima H, Tetreault LA, Nagoshi N, Nouri A, Kopjar B, Arnold PM, et al: Does age affect surgical outcomes in patients with degenerative cervical myelopathy? Results from the prospective multicenter AOSpine International study on 479 patients. J Neurol Neurosurg Psychiatry 13:470-477, 2015

22. Nouri A, Tetreault L, Singh A, Karadimas SK, Fehlings MG: Degenerative cervical myelopathy. Spine (Phila Pa 1976) 40:E675-E693, 2015

23. Ryken TC, Heary RF, Matz PG, Anderson PA, Groff MW, Holly LT, et al: Cervical laminectomy for the treatment of cervical degenerative myelopathy. J Neurosurg Spine 11:142-149, 2009

24. Santiago P, Fessler RG: Minimally invasive surgery for the management of cervical spondylosis. Neurosurgery 60 (1 Supp1 1):S160-S165, 2007

25. Skolasky RL, Albert TJ, Maggard AM, Riley LH III: Minimum clinically important differences in the Cervical Spine Outcomes Questionnaire: results from a national multicenter study of patients treated with anterior cervical decompression and arthrodesis. J Bone Joint Surg Am 93:1294-1300, 2011

26. Tetreault L, Goldstein CL, Arnold P, Harrop J, Hilibrand A, Nouri A, et al: Degenerative cervical myelopathy: a spectrum of related disorders affecting the aging spine. Neurosurgery 77 (Suppl 4):S51-S67, 2015

27. Tetreault L, Kopjar B, Côté P, Arnold P, Fehlings MG: A clinical prediction rule for functional outcomes in patients undergoing surgery for degenerative cervical myelopathy: 
analysis of an international prospective multicenter data set of 757 subjects. J Bone Joint Surg Am 97:2038-2046, 2015

28. Vernon H, Mior S: The Neck Disability Index: a study of reliability and validity. J Manipulative Physiol Ther 14:409415, 1991

29. Ware J Jr, Kosinski M, Keller SD: A 12-Item Short-Form Health Survey: construction of scales and preliminary tests of reliability and validity. Med Care 34:220-233, 1996

30. Whitmore RG, Ghogawala Z, Petrov D, Schwartz JS, Stein SC: Functional outcome instruments used for cervical spondylotic myelopathy: interscale correlation and prediction of preference-based quality of life. Spine J 13:902-907, 2013

31. Yabuki S, Kikuchi S: Endoscopic partial laminectomy for cervical myelopathy. J Neurosurg Spine 2:170-174, 2005

32. Zhou F, Zhang Y, Sun Y, Zhang F, Pan S, Liu Z: Assessment of the minimum clinically important difference in neurological function and quality of life after surgery in cervical spondylotic myelopathy patients: a prospective cohort study. Eur Spine J 24:2918-2923, 2015

\section{Disclosures}

The authors report no conflict of interest concerning the materials or methods used in this study or the findings specified in this paper.

\section{Author Contributions}

Acquisition of data: German, Abbas, Spurgas, Szewczyk, Yim. Analysis and interpretation of data: German, Abbas, Ata. Drafting the article: German, Abbas. Critically revising the article: German, Spurgas. Reviewed submitted version of manuscript: German, Spurgas. Approved the final version of the manuscript on behalf of all authors: German. Statistical analysis: Abbas, Ata.

\section{Correspondence}

John W. German, Department of Neurosurgery, Albany Medical College, 47 New Scotland Ave., MC-10, Albany, NY 12208-

34791.email: jwgerman@hotmail.com. 